\title{
LETTER
}

\section{Severity of post-cardiac surgery acute kidney injury and long-term mortality: is chronic kidney disease the missing link?}

\author{
Helmut Schiffl \\ See related research by Lopez-Delgado et al., http://ccforum.com/content/17/6/R293
}

While the retrospective cohort study by Lopez-Delgado and colleagues [1] suggests a strong association of the RIFLE classification and long-term mortality of acute kidney injury (AKI) after post-cardiac surgery, it has a number of limitations. The numbers of patients with pre-existing chronic kidney disease (CKD) or with nonrecovery of renal function, de novo CKD or progression of CKD to stage $\mathrm{V}$ are not given. The authors used an obsolete definition of CKD and a modified RIFLE classification system for definition and grading of AKI.

Taken together, numerous studies underscore the strong association between AKI and de novo CKD. Severity, duration and frequency of AKI as well as age, comorbidities and pre-existing CKD are known risk fac- tors for the development and/or progression of CKD [2]. Careful analyses of the cumulative mortality curves reported by Lopez-Delgado and colleagues or by our group [3] revealed a triphasic pattern. In the early phase, survival rates drop steeply due to critical illness, followed by a phase of smaller decline (caused by patient characteristics and development of CKD) and later on by a flatter survival curve attributable to the high cardiovascular mortality of progressive CKD [4]

Physicians need to consider the long-term sequels of severe AKI. Lopez Delgado and colleagues's study provides further arguments for an early follow-up of survivors of AKI by nephrologists.

\section{Authors' response \\ Juan C Lopez-Delgado, Francisco Esteve, Casimiro Javierre and Josep L Ventura}

We thank the authors for their comments and suggestions. Risk prediction in patients who suffer from postoperative AKI after cardiac surgery is becoming increasingly important today in decision-making regarding health care interventions. Thus, we agree that follow-up and long-term outcomes need to be reported as accurately as possible, especially for those patients who do not recover (totally or partially) renal function.

Nowadays, the definition of CKD is evolving and there are no definitive criteria [5,6]. In addition, development of risk scores for AKI corresponding to specific patient populations, such as cardiac surgery patients, is lacking

Correspondence: h-schiffl@t-online.de

Department of Internal Medicine IV, University Hospital Munich, Ziemssen

Street 1, D-80336, Munich, Germany
[7]. However, Englberger and colleagues [8] have provided an approach with a modified RIFLE score.

We must keep in mind the close relationship between renal and cardiac function. The development of a cardiorenal syndrome after cardiac surgery is one of the major causes of AKI [9]. As a consequence, the second phase with a smaller decline in survival rates could be caused not only by development of de novo CKD but also by poor cardiac function after cardiac surgery.

In our opinion, patients with AKI should be evaluated after surgery not only by nephrologists, but even by a team including different specialities to provide a multidisciplinary approach. 


\section{Abbreviations}

AKI: Acute kidney injury; CKD: Chronic kidney disease.

\section{Competing interests}

The authors declare that they have no competing interests.

\section{Published: 08 Apr 2014}

\section{References}

1. Lopez-Delgado JC, Esteve F, Torrado H, Rodriguez-Castro D, Carrio ML, Farrero $E$, Javierre $C$, Ventura JL, Manez R: Influence of acute kidney injury on short- and long-term outcomes in patients undergoing cardiac surgery: risk factors and prognostic value of a modified RIFLE classification. Crit Care 2013, 17:R293.

2. Chawla LS, Amdur RL, Amodeo S, Kimmel PL, Palant CE: The severity of acute kidney injury predicts progression to chronic kidney disease. Kidney Int 2011, 79:1361-1369.

3. Schiffl H, Fischer R: Five-year outcomes of severe acute kidney injury requiring renal replacement therapy. Nephrol Dial Transplant 2008, 23:2235-2241.

4. Schiffl H, Lang SM, Fischer R: Long-term outcome of survivors of ICU acute kidney injury requiring renal replacement therapy: a ten year prospective cohort study. Clin Kidney J 2012, 5:297-302.

5. Levey AS, de Jong PE, Coresh J, El Nahas M, Astor BC, Matsushita K, Gansevoort RT, Kasiske BL, Eckardt KU: The definition, classification, and prognosis of chronic kidney disease: a KDIGO Controversies Conference report. Kidney Int 2011, 80:17-28.

6. Rifkin DE, Coca SG, Kalantar-Zadeh K: Does AKI truly lead to CKD? J Am Soc Nephrol 2012, 23:979-984.

7. Roques F, Nashef SA, Michel P, Gauducheau E, de Vincentiis C, Baudet E, Cortina J, David M, Faichney A, Gabrielle F, Gams E, Harjula A, Jones MT, Pintor PP, Salamon R, Thulin L: Risk factors and outcome in European cardiac surgery: analysis of the EuroSCORE multinational database of 19030 patients. Eur I Cardiothorac Surg 1999, 15:816-822.

8. Englberger L, Suri RM, Li Z, Casey ET, Daly RC, Dearani JA, Schaff HV: Clinical accuracy of RIFLE and Acute Kidney Injury Network (AKIN) criteria for acute kidney injury in patients undergoing cardiac surgery. Crit Care 2011, 15:R16.

9. Kirklin JK, Naftel DC, Kormos RL, Pagani FD, Myers SL, Stevenson LW, Givertz $M M$, Young JB: Quantifying the effect of cardiorenal syndrome on mortality after left ventricular assist device implant. $\int$ Heart Lung Transplant 2013, 32:1205-1213.

$10.1186 / \mathrm{cc} 13820$

Cite this article as: Schiffl: Severity of post-cardiac surgery acute kidney injury and long-term mortality: is chronic kidney disease the missing link?. Critical Care 2014, 18:424 